\title{
TRABAJO, TIERRA Y COMUNIDAD: EL TÍTULO PRIMORDIAL de Santo Tomás de Ajusco y los Principios Vitales de UNA COMUNIDAD NAHUA COLONIAL *
}

\section{Daniel Astorga Poblete**}

\section{Resumen}

Este artículo analiza los elementos que construyen la relación entre comunidad y territorio entre los nahuas durante la colonia en el sector de Santo Tomás de Ajusco. Por medio de la lectura de su título primordial, se destaca la reciprocidad y equilibrio en el trabajo comunitario y en la relación entre la comunidad y la tierra basados en la construcción filosófica/ cosmogónica del pensamiento mesoamericano.

Palabras clave: México colonial, títulos primordiales, construcción del espacio nahua, tlacauhtli

\section{WORK, LAND AND COMMUNITY:}

\section{THE TITUlo PRIMORdial de SANTO TOMAS DE AJusco AND THE ESSENCE OF A NAHUA COMMUNITY IN COLONIAL TIMES}

\begin{abstract}
This article analyzes the elements that construct the relationship between community and territory among the colonial nahuas of Santo Tomas de Ajusco. By reading their primordial title, it is possible to observe the reciprocity and equilibrium in the communal work and the connection between community and land based on the philosophic and cosmological construction of the Mesoamerican thinking.
\end{abstract}

Keywords: Colonial Mexico, primordial titles, nahua space, tlacauhtli.

\footnotetext{
* “ "Este artículo se enmarca en el proyecto postdoctoral 'Resistencias Espaciales: El Título Primordial de Ajusco y el Manuscrito de Huarochirí como supervivencia del territorio." de la Pontificia Universidad Católica de Valparaíso.

** Chileno, PhD Romance Studies, Pontificia Universidad Católica de Valparaíso (Chile) - Duke University (USA).dea12@duke.edu
} 
Esta investigación comienza con la siguiente afirmación: en la América prehispánica no existía el espacio sino hasta la llegada de Colón. Esto no quiere decir que no existiera un territorio en donde los habitantes aborígenes desarrollaran su vida, sino que no existía la conceptualización de espacio debido a que esta pertenecía a la tradición occidental enraizada en las enseñanzas de Aristóteles, Euclides y Pitágoras. En América existían diversas conceptualizaciones que diferían en gran medida con la de espacio; y en México era tlacauhtli, arraigada en una visión de mundo completamente distinta a la que pertenece la idea de espacio. Lo anterior nos pone frente a dos problemas: ¿cuáles son las características de la conceptualización de tlacauhtli?, y ¿cómo se inserta la idea de espacio entre los pueblos aborígenes mexicanos? Para responder a estas preguntas utilizaremos como marco conceptual la teoría de matriz colonial de poder de Aníbal Quijano como una estrategia para desarrollar los procesos hegemónicos (o colonialidad) en América. Para este trabajo en particular nos enfocaremos en la arista económica de la matriz, relacionada con el domino del espacio. Posteriormente, nos enfocaremos en responder a la primera pregunta, para lo cual deberemos realizar una exégesis de diversos relatos ancestrales de la cultura nahua mexicana para definir el tlacauhtli. Luego, veremos como una comunidad se relaciona con el tlacauhtli mediante el trabajo de la tierra y el tributo (tequitl). Para responder a la segunda pregunta, describiremos cómo mediante la utilización de los recursos económicos de la tierra se intenta insertar una conceptualización de espacio entre los indígenas nahuas durante la colonia. Por último, utilizando la descripción del tlacauhtli y su relación con el tequitl, construiremos una matriz hermenéutica desde el pensamiento nahua para leer el relato de la comunidad de Ajusco sobre la fundación de su pueblo. El Título Primordial de Santo Tomás de Ajusco será un claro ejemplo de resistencia aborigen al concepto de espacio, ya que demostrará cómo una comunidad re-crea los principios fundamentales del tlacauhtli. 


\section{La hegemonización de la idea de espacio en América: un problema de colonialidad}

Para explicar cómo se produce un proceso de hegemonización de una idea utilizaremos la teoría de la colonialidad ${ }^{1}$. Ésta tiene como base la idea de matriz colonial de poder, la cual fue formulada por el sociólogo peruano Quijano en el ensayo "Colonialidad y Modernidad-Racionalidad" que aparece en el libro Los Conquistados: 1492 y la población indígena de las Américas (1992). En este texto, Quijano esboza la idea de que, a pesar de las guerras de independencia latinoamericanas que lograron formar las nuevas naciones libres del imperio español durante finales del siglo XVIII y comienzos del XIX y, por lo tanto, terminar prácticamente con el colonialismo ibérico en gran parte del centro y sur de América, la dominación por parte de los grandes imperios europeos continuó determinando no solo la vida republicana de las nuevas naciones, sino que también otros territorios en el orbe. Frente a tal realidad de sometimiento indirecto, Quijano propone que los grandes imperios europeos, al mismo tiempo que ejercían el colonialismo, estructuraron un poder de discriminación social codificados como "raciales", "étnicos", "antropológicos" o "nacionales", construcciones intersubjetivas las cuales fueron asumidas como categorías de pretensión "científicas" y "objetivas". A lo anterior, Quijano lo determinó como colonialidad. El desarrollo de la colonialidad, explica el grupo, va de la mano con el de la modernidad como proyecto conjunto que comenzó a formarse durante el 1500 en América pero que, desde entonces, tuvo una "vocación mundial." Walter Mignolo ha argumentado que la colonialidad es el

1 Las diversas teorías de mestizaje, aculturación, transculturación e hibridación no nos permiten entender cómo se produce la introducción de la idea de espacio dentro de los pueblos aborígenes americanos. En el caso del término de mestizaje, observamos que reproduce elementos de teorías biológicas de mezclas más que de procesos culturales. Por otro lado, la idea de aculturación que explica una determinación cultural de un grupo a otro diferente ya ha sido rebatida décadas atrás por Fernando Ortiz quien promueve la idea de transculturación como un procesos de modificación mutuo entre dos culturas. Sin embargo, tal conceptualización no explica por qué la visión de una cultura (en este caso, la idea de espacio) debe dominar y erradicar a la de tlacauhtli. Por último, la idea hibridación propuesta por Ernesto García Canclini entendida como la mezcla de estructuras discretas de dos culturas o más para formar nuevas estructuras, objetos y prácticas, pone demasiado énfasis al ámbito cultural, el cual sobredeterminaría las relaciones económico-políticas. En este caso, la propuesta de García Canclini no sirve ya que, dentro del ámbito espacial, muchos elementos económicos toman relevancia. Piénsese, por ejemplo, la perspectiva del espacio como un elemento privatizable, fuente de materias primas, las compra-venta de territorios, etc. Nos parece que una explicación que pueda tomar distintos ámbitos del proceso social (económico, político y epistémico) de hegemonización de una idea se amolda más a la propuesta de esta investigación. Por lo cual adoptamos la teoría de la colonialidad de Aníbal Quijano como nuestro marco conceptual para entender cómo es que la idea de espacio intenta insertarse y hegemonizarse dentro de la cultura de los nahuas de México. 
lado oscuro de la modernidad, en donde la segunda forma una retórica que "promete distintas formas de salvación económicas y subjetivas (de limpieza de sangre en un momento y de eugenésica en otro momento) de regulaciones morales y órdenes estatales (monárquicos, virreinales, estados seculares)" (10), y se podría agregar hoy en día, de desarrollo científico y tecnológico. Para llegar a tal punto de desarrollo, ese llamado ser moderno, es necesario, por parte de aquellos que no lo son, adoptar esa retórica y tratar de ser como las potencias. Sin embargo, y este es el punto interesante, para poder lograr cumplir esa retórica se deben asumir primero las diferencias y jerarquías, la colonialidad, que no han permitido a estos grupos sociales alcanzar esa promesa. La manera de insertar esta retórica de la modernidad, explica el grupo, se establece por una matriz de poder en la cual se ejercen los dominios de control y gestión de sociedades. Estos dominios son: a) control de la autoridad, b) control de la economía; c) control de la sexualidad y género; y, d) control del conocimiento y subjetividad. Al centro de esta matriz encontramos el racismo y patriarcalismo, los cuales son los pilares que sostienen la dominación de la matriz. En síntesis, la matriz colonial de poder nos entrega una explicación a la formulación del concepto de colonialidad, como la cara oscura de la modernidad. Cada eje de la matriz controla en diversos niveles a las sociedades que caen producto de ella. En la matriz, como explican Castro-Gómez y Grosfoguel, no existen jerarquías sino que heterarquías en donde ningún nivel gobierna sobre las demás sino que todos los niveles ejercen algún grado de influencia mutua en diferentes aspectos particulares y atendiendo a coyunturas históricas específicas (18). Esto quiere decir que, dentro de los cuatro segmentos de la matriz (economía, autoridad, conocimiento y género), ninguna de estas lógicas predomina sobre la otra. Por ende, una lectura economicista o una de género no son posibles ya que sus posiciones predominarían sobre otras en una realidad que está constantemente mezclándolas. Este artículo entiende el concepto europeo de espacio dentro de los procesos de desarrollo e implementación de la matriz colonial de poder en la América del siglo XVI a XVII. Nos interesa saber de qué manera esta matriz de dominación comienza a inventar el concepto de espacio en las culturas amerindias, y cómo esta invención es servil al proceso de colonización. En particular, en este artículo abordaremos cómo, desde el ámbito económico de la matriz colonial de poder, se inserta en el territorio mexicano un concepto de espacio el cual puede ser comercializado y 
considerado como propiedad privada, ajena al sujeto, lo cual choca con la perspectiva indígena de un tlacauhtli. Pasemos a ver, entonces, qué es tlacauhtli y cómo se relaciona con los sujetos nahuas no desde una perspectiva económica sino simbiótica.

\section{Tlacauhtli y su formación con el tonalli}

El concepto clave para entender la relación entre los nahuas con su territorio es tlacauhtli, el que pasaremos a desarrollar en la siguientes líneas. En su Vocabulario en lengua castellana y mexicana, Fray Alonso de Molina define tlacauhtli como "espacio de lugar, o cosa dejada, o sobras" (116). Al respecto, Miguel León Portilla ha esbozado una teoría con respecto al concepto. Para él, tlacauhlti tendría una estrecha relación con el vocablo cahuitl, que corresponde a la palabra "tiempo" en español. Ambos vocablos en náhuatl estarían derivados del verbo cahua, que vendría a significar "dejar algo o llevar alguna cosa a otra parte" (Molina 44). Por lo tanto, según León Portilla, "El denominador de ambos conceptos es 'dejar', 'ir dejando', cuando se refiere al tiempo y 'haber sido ya dejado permanentemente', cuando se refiere al espacio" (Toltecayotl 181). Un ejemplo de esta relación aparecería en el códice Fejérváry-Mayer². (Fig 1) Ahora bien, para que exista el movimiento (ollin) en el tlacauhtli, debe existir una fuerza cósmica que provea de la energía suficiente para que el sol comience a girar en las cuatro partes. Esta energía se denomina tonalli, la cual se libera en el universo gracias a la separación

2 Lo que nos muestra este códice es una expresión de la organización del tiempo y de lo que nos rodea. Por un lado, tlacauhtli se organiza en cinco ejes distribuidos en cuatro direcciones y un centro. Comenzando desde arriba y en sentido contrario a las manecillas del reloj, tenemos Tonatiuh ichan, "la casa del sol". En esta dirección, que corresponde al Oriente, tenemos a cada lado a Iztli y a Tonatiuh. En la dirección correspondiente al Norte, están los dioses Tlaloc y Tepeyollotl. Luego, tenemos Cihuatlampa, "el lado de las mujeres", correspondiente al Poniente, con dos diosas: Chalchiuhtlicue y Tlazolteotl. Por último, tenemos la dirección Sur a la que los nahuas llamaban Mictlampa que señalaba "el rumbo del reino de los muertos". Aquí podemos observar a los dioses Cinteotl y Mictlantecuhtli. En el centro de esta cuatripartición tenemos a Xiuhtecuhtli, Señor del Fuego; y dividido en cuatro partes (cabeza, mano, pierna y costillas), a Tezcatlipoca. Ahora bien, a pesar de ser una referencia de los puntos cardinales de lo que nos rodea, este códice también explica la idea de lo que va siendo dejado en el tiempo (cahuitl). Junto con la organización cosmológica en cuatro divisiones más un centro, tenemos la estructuración del tiempo llamado tonalpohualli. Los aztecas usaban un calendario sagrado consistente en veinte trecenas ( $20 \times 13=260$ días), lo que marcaba un año. Si observamos los trapezoides que encierran a los dioses de cada orientación cardinal y los lazos que los unen, encontraremos un camino marcado por 12 días más uno de los veinte signos. Los aztecas contaban los días de 1 a 13, con un signo entre los veinte diversos. Si comenzamos a leer desde el día 1 Cipactli (Lagarto), que se encuentra en el extremo inferior derecho del cuadrante del Oriente, tendríamos que seguir la cuenta 2 Ehecatl, 3 Calli, etc., hasta llegar a 13 Acatl, en donde comenzaría una nueva trecena con 1 Ocelotl. Esto nos daría una estructura de cinco signos para cada rumbo espacial conformados por las cuatro signos del trapezoide más un quinto signo del lazo a su izquierda. 
que acontece a Ometéotl cuando su cuerpo se divide en Ometecuhtli y Omecihuatl ${ }^{3}$. Como explica Jacques Soustelle: “Ometecuhtli es el dios protector del primer signo del calendario, Cipactli, el monstruo mítico que lleva la tierra sobre su espalda. Omecihuatl es la patrona del último signo, Xochitl, la flor..." (99). Este ser primigenio era sustancia, la cual se dividió en dos partes opuestas y complementarias: la tierra y el cielo. De esta división se liberaron sustancias divinas las que crearon a los cuatro dioses: Tlatlauhqui Tezcatlipoca, Yayauhqui Tezcatlipoca, Quetzalcoatl y Huitzilopochtli. Dos de estos dioses, Quetzalcoatl y Huitzilopochtli crearon a Cipactli, una especie de caimán sobre el cual hicieron la tierra ${ }^{4}$.

Observando la división cuatripartita del mundo en el Códice Fejérváry-Mayer, podemos entender análogamente estos cuatro postes que soportan la división del mundo. La energía divina que estos cuatro dioses expulsan luego de su sacrificio se convierte, entonces, en las esencias de los hombres, animales, piedras, montes, agua, etc. Así, como argumenta López-Austin: “Los dioses actúan cíclicamente en el mundo. La sustancia divina es enviada a la tierra en forma de tiempo, de destino. Esto hizo que el calendario mostrara las combinaciones de las distintas fuerzas de los dioses. Todos ellos entraban en el juego de jerarquías y dominios." (28) En otras palabras, la organización del mundo se da en la interacción y alternancia de estos cuatro dioses en los cuatro costados

3 De acuerdo a la Historia de los Mexicanos por sus Pinturas que aparece en León-Portilla (1961) en un principio no existía nada, solo una esencia, un dios llamado Ometeotl, que en sí era una dualidad compuesta por Ometecuhtli (Señor de la dualidad) y Omecihuatl (Señora de la dualidad). De este dios nacieron cuatro hijos: Tlatlauhqui Tezcatlipoca, Yayauhqui Tezcatlipoca, Quetzalcoatl y Maquizcoatl (Huitzilopochtli para los aztecas). Luego de un tiempo, Quetzalcoatl y Huitzilopochtli convinieron en hacer el mundo y, además, los trece cielos, el inframundo, la tierra, el calendario y a los primeros hombres. Sin embargo, a falta de un Sol que alumbrara al mundo, cada dios decidió tomar éste rol. De esta manera, Tezcatlipoca se convirtió en Sol en un primer momento, lo que duró 676 años. En esta época, en donde los hombres (macehualtin) solo se alimentaban de piñones, fueron creados los gigantes, quienes murieron cuando Quetzalcoatl golpeó a Tezcatlipoca quien cayó al agua convertido en un tigre. Así, Quetzalcoatl tomó el rol del Sol por 676 años hasta que Tezcatlipoca, convertido en un tigre, le dio un zarpazo y lo derribó, creando un viento que asoló todo a su paso incluyendo a los macehualtin. Solo algunos de estos pudieron sobrevivir, y esos son hoy en día los monos. Tlatocatecuhtli, entonces, decidió ser el nuevo Sol. El Dios del Infierno cumplió este puesto por 364 años, tiempo en el cual el alimento era el acicintli. Haciendo llover fuego, Quetzalcoatl termina con el reinado de este dios para que asumiera Chalchiuhtlicue, su esposa, quien fue el Sol durante 312 años. Durante esta época, el alimento era el cincocopi. Este reinado terminó cuando un gran diluvio destruye el mundo. Preocupados por el devenir de la tierra, los dioses deciden reunirse para restaurarla, para lo que crean cuatro hombres que los ayudasen a hacer cuatro caminos desde el centro de la tierra para entrar y levantar el cielo.

4 Explica López-Austin: “Una vez creados la tierra y el cielo a partir del cuerpo de Cipactli, y con ello constituida la gran división entre la parte femenina y la masculina del cosmos, los cuatro postes- o árboles o dioses u hombres- se convirtieron en los caminos de los dioses. Fueron los caminos de los dioses porque por su tronco hueco correrían y se encontrarían las esencias divinas opuestas que eran los flujos de las dos mitades del cuerpo del monstruo" (19). 
del mundo, para dotar a éste y a sus habitantes de las esencias necesarias para el subsistir del mundo y de los sujetos. Tal alternancia continua y cíclica permite el movimiento (ollin) del llamado quinto sol, y esta alternancia permite que los dioses interactúen en un constante nepantla, una organización equilibrada pero delicada entre ellos.

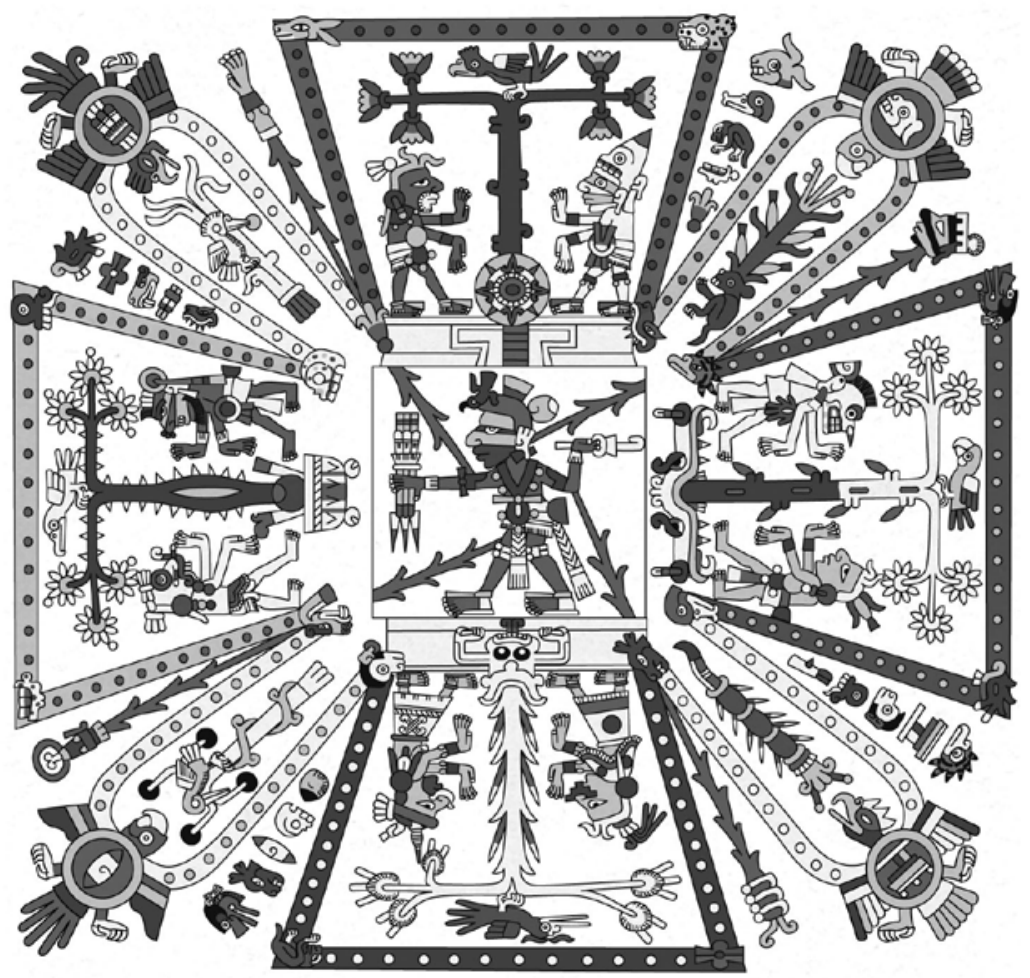

Figura 1 Primera página del Códice Fejérváry-Mayer

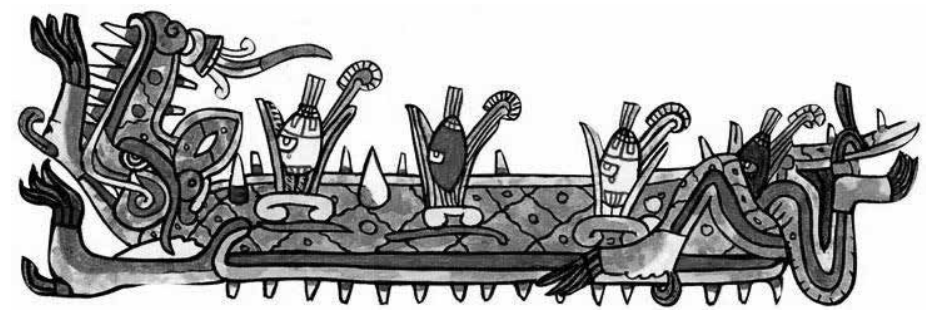

Figura 2 Cipactli, el mundo, en el Códice Borgia, página 27 
Ahora bien, la comunidad toma esta organización del mundo como la base de su propia estructura en cuanto a su relación entre los sujetos de la comunidad, por un lado, y la comunidad y la tierra, por el otro. En otras palabras, lo que la comunidad debe asegurar es el flujo constante y equilibrado de las fuerzas entre los hombres por medio de la regulación del tequilt (el trabajo y tributo) para así regular la relación constante y equilibrada entre comunidad y tierra por medio del tonalli que circula entre ambas. Por lo tanto, veamos en un primer momento, qué es y cómo se relaciona el tequitl con la comunidad, y después analicemos como el tequitl pasa a ser el tonalli que circula entre tierra y comunidad para así abrochar su relación. Lo anterior nos ayudará a entender el sentido profundo del relato del Título primordial de Santo Tomás de Ajusco.

\section{Tequitl y comunidad}

El término tequitl corresponde a la idea de tributo u obra de trabajo. Pedro Carrasco (1978) explica que el tequitl es el trabajo administrado políticamente, un trabajo de cualquier tipo (agricultores, artesanos, sacerdotes, políticos, etc.) que toma forma de tributo a la entidad política controladora. De aquí a que todos los que componen el altepet $l^{5}$ deban dar algún tipo de tequitl, generalmente por medio del trabajo, aunque algunas veces se aceptaba el pago del tributo por medio de especies (Carrasco 30). Este trabajo no era ajeno a nadie, aunque en su mayoría, el tributo era entregado por el macehual para el mantenimiento de los pipiltin a cambio del uso de la tierra y el control del usufructo de ésta. El excedente del trabajo de la tierra, en este caso, resultaba ser el tributo que era entregado a la clase política distribuidora. Una manera de explicar por qué los participantes de una comunidad deciden "dar tributo" o su trabajo a la clase de los pipiltin proviene del análisis de los nahuas de Guerrero en la actualidad que realiza la antropóloga Catherine Good. La autora amplía la definición del término explicando que el tequitl

5 Entenderemos al concepto prehispánico de altepetl como una organización comunitaria políticoreligiosa ligada a un territorio, con una historia particular de migración para fundar su "ciudad", una estructuración social tanto en el sector religioso como político-jerárquica, pero no desde el punto de vista europeo. El acceso a algún monte o cerro, tanto natural como artificial, además de la cercanía a fuentes de agua también marcaban la idea fundamental de altepetl, tal como lo señala su término (in alt in tepetl, "las aguas, las montañas). Finalmente, éste posee una arquitectura políticoreligiosa además de un centro comercial para realizar el intercambio de alimentos y el pago de tributos. 


\section{implica vigor y poder personal, una transmisión de energía y fuerza ${ }^{6}$.} Esta fuerza que se transmite desde la persona que trabaja hacia los que reciben los beneficios y viceversa en una comunidad por medio del tequitl corresponde a la energía vital del tonalli, la que otorga calor corporal al ser humano según las creencias nahuas, pero que también se involucra en la creación del mundo por medio de la separación del cielo con la tierra, así como en la relación sexual (López-Austin: 1994; Sigal: 2011). Así como esta fuerza circula gracias a la creación del mundo, también debe circular por medio del trabajo. Good explica que las relaciones sociales se construyen por medio de la circulación del trabajo y reciprocidad entendida como "amar" y "respetar" (92) .

6 Explica Good: "Este concepto incluye todas las actividades necesarias para la producción material pero no las privilegia y tequitl abarca también a acciones tan diversas como las siguientes: hablar a otros, dar consejos, persuadir o convencer; compartir conocimientos, enseñar algo a otro; curar, hacer ofrendas, rezar; cantar, bailar, tocar música. Tequitl se aplica además a las relaciones sexuales, la reproducción biológica, la muerte; al tomar y comer en fiestas, participar en rituales, acompañar a otro como parte de "su gente" en algún acontecimiento público. Para resumir brevemente, tequitl es un concepto amplio que los nahuas usan para referirse a todo uso de la energía humana, física, espiritual, intelectual, emocional para realizar un propósito específico; va ligado con un concepto de energía vital, fuerza o chicahualiztli [...]" (91).

7 En el análisis de Carrasco, la economía azteca se divide en dos estamentos: los pipiltin, la clase dominante que controlaba los medios materiales de producción, y los macehualtin, la clase trabajadora dependiente política y económicamente de la primera. El medio de producción más importante dentro del sistema azteca era la tierra y la fuerza que la trabaja (los macehualtin). Ahora bien, dentro de este sistema, la tierra era un bien de la comunidad y no era una propiedad de los pipiltin, aunque estos las distribuyesen dentro de toda la comunidad. Tal distribución se realizaba de acuerdo a la función que cumpliese el sujeto dentro de la sociedad. Los pipiltin tenían sus tierras asignadas (pillalli), las cuales eran trabajadas por los macehualtin adscritos a ellos. De aquí a que existiesen tierras del linaje noble (tecalli), tierras del tlatoque (tlatocamilli), tierras de palacio (tecpantlalli), y tierras del templo (teopantlalli), etc. Hay que mencionar que estas tierras no pertenecían a estos sujetos sino que a sus cargos políticos, y éstas les eran otorgadas mientras cumpliesen las funciones asignadas. Una vez que su función terminaba, las tierras y los macehualtin eran otorgados al nuevo funcionario. Como menciona Carrasco, estas tierras eran otorgadas y trabajadas tanto para el sustento de los funcionarios de la clase "dominante" adscritos, como también a los macehualtin que las trabajaban. Por otro lado, el macehual recibía tierras como miembro de un calpulli que tributaba a un tlatoani, las cuales eran trabajadas como sustento de su familia y en donde el excedente iba a parar como tributo. De aquí a que encontremos las tierras calpullalli, tierras de los macehualtin, las cuales no eran alienables y que se trabajaban en común aunque existiesen divisiones para cada hogar, y que eran administradas por los calpolli como unidad corporativa y responsabilidad colectiva por el pago del tributo. Como señalamos anteriormente, la producción era controlada por el organismo político el cual distribuía tanto las tierras como la tributación, la cual siempre seguía un esquema redistributivo, elemento necesario para entender la idea del tequitl desde una perspectiva amplia. Sabemos que los productos trabajados y entregados como tributo, los cuales conformaban el excedente de lo producido por los macehualtin en cualquier tipo de tierra, se acumulaban en el palacio (tecpan). Los señores los guardaban y recibían para su uso o para atender sus obligaciones, pero también para las campañas militares, las ceremonias, festividades, casamientos, funerales, etc. También, durante épocas de crisis, el tributo guardado servía respaldar a la comunidad frente a una mala cosecha o a una merma de trabajadores. En otras palabras, si hay una acumulación del tequitl, ésta funcionaba para atender las necesidades de la población en general, en donde se beneficiaban todos. Por ende, el tequitl debe ser pensado en cuanto a un producto de las fuerzas del sujeto (del tonalli) que debe circular en el mundo con los otros y con la tierra. 
Ahora bien, el tequitl es lo que permite hacer comunidad, pero es también lo que le da la identidad a una persona dentro de esta comunidad. Aquí, los sujetos se hacen en cuanto a que trabajan la tierra y entregan su esfuerzo a la comunidad, el cual será devuelto por ésta mediante la redistribución y reciprocidad del tequitl. Good nos remarca que: "Cuando una persona trabaja, transmite su fuerza a otras, cuando recibe beneficios del trabajo del otro, uno también recibe su energía vital" (97). Entonces, podríamos inferir que el tequitl es una entrega recíproca del tonalli por los sujetos. No es sólo un tributo por el derecho a trabajar la tierra a la clase dominante, ni tampoco el pago a ésta, sino que el trabajo, el esfuerzo de cada sujeto de la comunidad en pro del buen vivir de ésta, no importando la labor que cumpla, los años, su género, etc., y que debe funcionar en base a la reciprocidad. Por ende, tanto el trabajo del tlatoani como el del macehual es vital en cuanto a que sostiene la intrincada relación de las fuerzas vitales de los sujetos de la comunidad. Es en este momento en que la circulación del tonalli por medio del tequitl actualiza el funcionamiento del mundo tal como los dioses interactúan alternadamente para sostener al mundo en el caso de la creación de éste.

Si el tequitl señala la reciprocidad de las fuerzas entre los sujetos de la comunidad, la idea de restitución también aparece con respecto a la tierra $^{8}$. La comunidad, por ende, debe entenderse con la tierra, darle su tequitl, entregarle su tonalli, para que la reciprocidad de las fuerzas continúen y así ésta pueda subsistir. En este sentido, la relación entre tierra y los productores del trabajo escapa de la mirada netamente económica sino que se alza como una intrincada red en donde la tierra no es vista como un ente de donde se obtiene un producto, sino que el otro polo de una actividad cósmica en donde el universo pone las reglas. Acá no existe un logos pensando el topos, sino que un topos que dictamina el ritmo de la vida comunitaria, del trabajo y de la economía. Esta es la relación que establece el pueblo de Ajusco con su tierra y la que intentan mantener en su Título Primordial, y no la que dictaminaba el proceso colonial de la época y su acercamiento a la tierra.

8 De aquí a que lo que entrega la tierra sea devuelto a esta en una circularidad primordial. LópezAustin (1994) nos señala, con respecto a las ceremonias agrícolas entre los nahuas, que: “Uno de los puntales de la idea del ciclo es el de la restitución. Debe devolverse a los dioses virtualmente, todas las fuerzas necesarias para producir lo recibido. La devolución debe ser hecha por una vía que sea de igual naturaleza a lo restituido [...] La restitución- el ritual religioso- es así, en buena parte, el manejo de las fuerzas sobrenaturales, la propiciación del retorno de la reproducción por los cauces que el ser humano necesita para vivir" (204-205). 


\section{Colonialidad y la introducción del espacio en el México colonial}

La inquietud económica con respecto al comercio y al trabajo de la tierra siempre estuvo presente dentro de las justificaciones argumentadas por las élites intelectuales con respecto a la apropiación del territorio americano por parte de los imperios en formación en el siglo XVI y XVII. Por ejemplo, el padre Francisco de Vitoria declara que el reino de Castilla entra en una guerra justa con las "naciones" de las Indias siempre y cuando éstas se nieguen a darles libre paso a los comerciantes españoles para transar, como se puede leer en sus Relectio de Indis. Por otro lado, John Locke justifica la apropiación del territorio americano a manos de los colonos en cuanto a que si éste se encuentra en un estado "natural", en donde los hombres no han intervenido para trabajarlo, cualquier persona tiene el derecho de poseer aquella tierra siempre y cuando la produzca, dejando de lado las actividades nómadas que realizaban muchas comunidades indígenas. Los argumentos siempre son variados, y apuntan a distintos elementos, aunque lo interesante para nosotros es que la tierra y su producción en beneficio de los imperios siempre fueron preocupaciones de primer orden en el desarrollo de la colonialidad. En el caso del valle central de México, el control de la tierra, del trabajo y del comercio, resultaron ser necesarios ya en los primeros años luego del arribo de Cortés. La manipulación del aspecto económico del territorio intentará presentar al espacio como un elemento servil a la comunidad, un objeto al cual trabajar. En este sentido, el espacio es donde se obtienen las materias primas y el alimento para vivir, pero no en una relación complementaria y redistributiva como en el caso del tequitl.

En el caso del territorio mexicano, a pesar de que en mayor medida la corona española reconoció la propiedad de muchas tierras a las comunidades indígenas, parte del territorio fue usurpado bajo distintos argumentos tales como la venta de tierras por parte de indígenas a españoles (siempre bajo sospechosos acuerdos), la concesión de tierras por parte de los indígenas a Hernán Cortés por ser éste quien los liberase del yugo de la Triple Alianza, etc. Sin embargo, como explica Gibson (1964), la mayor parte del territorio siguió siendo dominio de los indígenas durante los primeros años de la colonia debido a los beneficios tributarios que el sistema colonial obtenía por la producción del territorio, el cual se vio modificado por la encomienda y las reducciones (222). Dentro del sistema 
azteca de tributos, los excedentes de la producción iban a un gran centro, México-Tenochtitlan, y a los distintos mercados de la alianza en donde se volvía a redistribuir a las periferias de la organización. Sin embargo, bajo el dominio colonial, el sistema tributario se modificó excluyendo el gran centro y sólo manteniendo en pie el sistema altepetl-calpolli que pasó a ser cabecera-sujeto. Bajo esta ordenación, la dirección del tributo que producía el sujeto iba a parar a las manos de la cabecera, la cual generalmente correspondía a los territorios de un encomendero. Este paradigma económico alteró en cierta medida la relación del indígena con la tierra y el trabajo.

El mismo Gibson nos indica que el trabajo dejó de ser visto como una actividad alegre y ceremoniosa, relacionada con un desarrollo social, moral y espiritual para dar paso a una perspectiva económica y física a la manera europea (221). La idea del trabajo indígena no recompensado fue explotado por la encomienda a pesar de que la corona intentaba prohibir el trabajo no remunerado. Si en la época pre-cortesina los indígenas obtenían de la tierra lo que necesitasen, ahora todo debía ser comprado y vendido, entregado en tributo, aunque muchas veces ya faltase mano de obra para trabajar las tierras. El sistema del repartimiento racionó el trabajo rotativo con fines públicos, aunque los indígenas ya no viesen que las obras en construcción cumpliesen un rol fundamental para su vida diaria. El trabajo rotativo era forzosamente necesario para enfrentar una baja de población indígena apta para trabajar. Debemos recordar que las enfermedades, los enfrentamientos bélicos, la hambruna y el trabajo forzado incidieron en un declive de alrededor de un 78 a 95\% de la población indígena de acuerdo a Cook y Borah (1960). Los indígenas sobrevivientes, repartidos entre el trabajo de la encomienda, de las propiedades de las comunidades y de españoles, conformaban la mano de obra que suplía de alimentos y recursos al sistema colonial. Éste ya no era un trabajo, un tequitl recíproco y redistributivo, sino que un nuevo formato de esclavitud para una clase dominante. En cuanto a las tierras, mayormente la clasificación que existía previamente se fue desintegrando. Las teotlalli, las tierras de los templos trabajadas para las ceremonias religiosas, dejaron de ser utilizadas para esos fines. Las tecpantlalli, tlatocamilli y pillalli también fueron extinguiéndose o fueron absorbidas por los encomenderos, vendidas o dadas en arriendo. Debemos tener en cuenta que frente al declive de la población indígena, muchas tierras quedaron sin personas que las trabajasen y disponibles 
a la corona para ser reasignadas. Muchas veces, sin embargo, algunos nobles indígenas que clamaban por la propiedad de tierras de acuerdo a su alto grado no eran tomados en cuenta como los verdaderos propietarios de los territorios y, por consiguiente, estas propiedades eran confiscadas. Por otro lado, las calpullalli fueron reasignadas como las tierras de las comunidades y de las cuales se obtenían los productos que después iban a parar como tributos. Una vez introducido el concepto de tierra alienable, muchos indígenas, frente a momentos de angustia económica por tributos que pagar, podían vender tierras que les eran de su propiedad de acuerdo a las normas españolas. Sin embargo, aquellas que eran de la comunidad eran inalienables aunque muchas veces trataron de ser obtenidas por encomenderos o hacendados. Frente a la amenaza de la expropiación, las comunidades, mediante la figura de la corporación, solicitaban las llamadas "mercedes de tierras" dentro del marco legal colonial español para asegurar la propiedad de estas tierras y el usufructo de ésta para pagar los tributos requeridos por la corona. De esta forma, el calpulli, ahora sujeto, intentó mantener su relación comunal con la tierra y el trabajo, a pesar del tipo de economía de extracción que primó en el México colonial. Lo interesante de esta situación es que muchos de los títulos primordiales, los documentos que los indígenas ocupaban como pruebas de propiedad de las tierras, reafirmaban las relaciones que estos tenían no con la tierra y su historia a la manera de un título de propiedad europeo, sino que con el tlacauhtli, el tequitl y el tonalli al estilo de los amoxtli. En otras palabras, los títulos primordiales guardan otros aspectos de la relación de la comunidad con su territorio y que van más allá de lo netamente legal como lo hace el Título primordial de Santo Tomás de Ajusco.

\section{El Título primordial de Ajusco y la resistencia del vínculo comunidad-Tlacauhtli}

Los títulos primordiales de los pueblos mesoamericanos comienzan a aparecer luego del proceso de composición de tierras ejecutado por la corona española al mando de Felipe III en 1591. Las composiciones de tierras funcionaron como una manera de reasignar los terrenos baldíos y no cultivados, y se ejecutaron durante los períodos de 1642 a 1644, y de 1692 a 1754, época en donde encontramos más títulos primordiales debido a la estabilización de la población indígena. Para respaldar la 
posesión de los terrenos, la corona solicitaba que los títulos presentasen versiones revisadas de la historia del pueblo (las cuales muchas veces iban acompañadas de mapas y amoxtli), ${ }^{9}$ resúmenes de las extensiones de la antigua jurisdicción del pueblo, los santos patronos del lugar, y los límites demarcados del altepetl con sus vecinos. En el caso del Titulo primordial de Santo Tomás de Ajusco, éste proviene de lo que antiguamente se conocía como Axoxpan y que, previo a Hernán Cortés, se encontraba en la zona montañosa de Ajusco entre tres volcanes. Luego de los primeros años de la colonia, el pueblo se asentó en dos sitios, a medio kilómetro de distancia, dando comienzo a Santo Tomás y San Miguel. Debido a que el pueblo pertenecía al Marqués de Oaxaca, por medio de Coyoacán, los habitantes de Ajusco pudieron sentirse amenazados de perder sus tierras a manos de los encomenderos y terratenientes que compraban terrenos gracias a la intervención de Cortés. Tal temor no era en vano ya que, para 1620, muchas tierras de Ajusco habían sido vendidas, y la sobreexplotación de la mano de obra indígena calaba hondo en el pueblo, lo que se sumaba al proceso de congregación del pueblo en 1603 y 1604 . A lo anterior se le sumaba la confección de nuevos límites del pueblo que lo dejaba con 12.000 hectáreas. AAjusco, el proceso de composición de tierras llegó entre 1712 y 1745, en donde fue presentado el título primordial. Sin embargo, según Amos Megged (2010), este título fue compuesto en 1609, paralelo al proceso de congregación de los indígenas y a la primera ola de composición de tierras, como una manera de salvaguardar la historia y los límites de Santo Tomás de Ajusco ${ }^{10}$.

El título comienza con el discurso del señor de Tecpanecatl en el año 1531 narrando las atrocidades cometidas a los nahuas por parte de Cortés y los demás españoles entre 1520 y 1531 como, por ejemplo, la quema del gobernante Caltzonzin por parte de Nuño de Guzmán en 1530 junto con la ejecución de otros tlatoque ${ }^{11}$, y en paralelo menciona las vejaciones

9 Amoxtli es el término empleado en náhuatl para referirse a los libros que contenían información referente a los anales históricos, calendarios, mapas, etc.

10 Para el siguiente análisis, tomaremos tanto la versión de Chimalpopoca como la del fondo LafraguaPuebla disponibles gracias a Amos Megged (2010).

11 Tlatoani (tlatoque sing.) es definido por Frances Karttunen como: "hablador o gran señor, el rey, el gobernador, autoridad (del pueblo), jefe, presidente" (266). Con respecto a la definición, debemos señalar que tlatoani (tlahtoani), proviene de la palabra tlahtoa que significa "hablar, proclamar y ordenar". Por lo tanto, el tlatoani es quien tiene la voz conductora dentro del altepetl, quien habla en los consejos y a quien se le escucha. Además de presidir el consejo de ancianos e importantes dentro de la comunidad, siempre que se enfrentasen a un tiempo de guerra o una mala cosecha o que se planease alguna edificación o modificación a la estructura del altepetl, el tlatoani estaba a cargo de la distribución de los tributos y de la mano de obra por parte de los macehualtin. 
cometidas a las mujeres, los robos de tierra y la sed de metales preciosos. Luego, el tlatoani comienza a aconsejar a sus "hijos" (el pueblo) que deben conocer quiénes son los verdaderos propietarios de estas tierras: sus antepasados, en miras de los nuevos gobernantes quienes intentarán arrebatárselas por medio de la congregación o el despojo directo gracias a Hernán Cortés. Posteriormente, comienza la narración de la fundación del pueblo, definiendo los accidentes geográficos que marcan los límites de éste, afirmando su heredad por parte de la comunidad y bosquejando la estrategia de convertirse al catolicismo para salvaguardar la propiedad de las tierras comunitarias. Por último, en la versión del fondo LafraguaPuebla, se reafirma la idea de la conversión al cristianismo para salvaguardar las tierras y se enumeran los límites mediante una narración "caminada" sobre estos, para finalmente recordar a la comunidad que se debe proteger la tierra y mantenerla en el futuro.

Ahora bien, este título, como muchos otros, no está dirigido al gobernador, al corregidor o a otro funcionario de la corona sino que a la comunidad del pueblo, en donde el tlatoani Tecpanecatl constantemente los interpela: "Amados hijos míos" (Notlazopilhuane); "Ustedes deberían hacerse conscientes de que únicamente desean mandar" (Xicmomachitican ca ipampa zan yehuantin zan quinequi tlatocatizque); “QQué deberíamos hacer, mis hijos?" (Tlein tic chihuazque nopilhuan?). Al establecer una especie de diálogo entre el tlatoani y su comunidad, el título primordial remite a los consejos comunales que se daban en la época pre y post-colonial cuando el altepetl se enfrentaba a crisis que debían ser superadas en conjunto. El consejo constaba de los tlatoque del pueblo o de los tlamatinime ${ }^{12}$, y cada uno expresaba su opinión por medio de un discurso. También podríamos señalar como antecedente a los huehuehtlahtolli, los testimonios de la antigua palabra, los cuales eran discursos de los viejos sabios a los jóvenes acerca de la manera de criar a los niños y niñas, las instrucciones de comportamiento frente a determinados eventos, etc. Las preguntas y las indicaciones del tlatoani Tecpanecatl bien podrían apuntar a estos tipos de discurso, en donde la oralidad juega un rol primordial. Además, frente al problema que significan las reducciones del pueblo, expropiaciones de tierras, vejaciones a las mujeres y el asesinato de los grandes tlatoque, la gran crisis que está sufriendo el pueblo, el título primordial hace texto al consejo comunitario, funcionando como la voz de la comunidad y cohesionándola frente a este

12 Los tlamantinime son considerados como sabios sacerdotes dentro de la cultura nahua. 
momento de algidez. Por ende, lo que busca la comunidad en su título primordial es afianzar la sobrevivencia del pueblo, y esto sólo se relaciona con asegurar las tierras de ésta:

[...] y por que desean apropiarse de nuestras tierras, y todo es de nuestra propiedad, nuestros abuelos, quienes fueron los primeros en ver las cosas claramente aquí, han hecho un gesto de reverencia [profecía] allá abajo [junto a las tierras], de que otra gente vendrá desde lejos, para con gritos hacernos obedecer y desalojarnos por la fuerza, se apropiarán todas sus, extensas y respetadas tierras [... ${ }^{13}$ (Megged 148)

Este discurso, que busca crear conciencia en la comunidad del peligro de perder las tierras, aparece de manera similar en diferentes títulos en donde, como explica Enrique Florescano:

[...] estaba dirigido especialmente a los jóvenes, que recordaba la tarea colectiva de proteger las tierras. Representaba la palabra de los padres fundadores y tenía el propósito de mantener viva en la memoria la idea de que la supervivencia del pueblo dependía de la conservación de las tierras comunales. (187)

Dado lo anterior, cabe preguntarse por qué el título relaciona la tierra con la comunidad. Una manera rápida de responder a esta pregunta sería señalar que la tierra sirve de subsistencia a la comunidad abasteciéndola de alimentos, tierras y cobijo. Bajo esta idea, ligada más a un pensamiento occidental sobre el espacio en donde éste "sirve al hombre" y no viceversa, se oscurece intrincadas relaciones entre comunidad y tierra que observaban los nahuas de la época. Tampoco queremos señalar solamente que una comunidad "pertenece a un lugar determinado", ya que la idea de "pertenencia" o "relación" entre un lugar determinado y una comunidad puede variar drásticamente entre diversas culturas cuando éstas conciben su entorno o "espacio" de manera diferente. Es por esto que el Título Primordial de Ajusco nos puede resultar interesante ya que da señas de la relación entre tierra y comunidad, o mejor dicho, entre tlacauhtli y altepetl, desde la perspectiva nahua. Por ende, es necesario explorar cómo consideran los nahuas lo que es tlacauhtli (su

13 yuan ipampa ca quinequi quimoaxcatizque in totlahuan yuan mochin quexquich totlatqueiuh tocolhuan achtopa tlanextli nican oquimoittiyique ompa tlaltzintla oquimotlahuique ca hualazque occequintin huecatlaca techtlaocolmacacuihui, techquixtiliquihue quimoaxcatizque cenca mahuiztic cenca huey totlal... 
espacio), su funcionamiento y la interrelación vital entre el altepetl y éste. Observaremos que, en el caso nahua, la ligazón entre comunidad y tierra obedece a la circulación de fuerza vital (tonalli) entre ambos polos, lo que permite no solo la subsistencia de la comunidad, sino que también la de la tierra.

En el Título, se fundamenta en lo que hemos señalado más arriba: el trabajo, tequitl, forma comunidad. En otras palabras, la comunidad no solo se asienta en la tierra, en un lugar físico, en la naturaleza, sino que también en el tequitl que se da en ésta y que involucra tanto al entorno como a los sujetos que viven en ella. Comunidad se hace sólo si es que hay una relación recíproca entre los individuos entre sí y entre los individuos con la tierra. De aquí a que la relación comunidad-tierra sea fundamental para la supervivencia de un pueblo, ya que asegura la armoniosa relación de las fuerzas -el tonalli-, de los sujetos y del mundo. Esta cohesión primordial incluso va más allá del tiempo. Megged nos recuerda que los saltos de tiempo hacia delante y atrás en las narraciones de los diferentes títulos primordiales corresponde a cómo concebían los nahuas el destino. En este sentido, los títulos primordiales funcionan como receptáculos de tiempo, en donde la memoria actualiza distintos eventos conectados con la tierra. Las fuerzas de la comunidad, el tequitl de cada uno de los habitantes que fundaron y formaron el altepetl, están presentes en el título por medio de estos saltos de tiempo. Son estas fuerzas las que quedan rondando en el territorio, las que contribuyen a su supervivencia y las que deben ser atestiguadas.

Por lo anterior, el título primordial, podríamos afirmar, no es una mera "representación" del territorio, del tlacauhtli, sino que es el tlacauhtli, el tiempo/espacio en donde ocurren los eventos. $\mathrm{Si}$, por un lado, la corona española solicitaba un resumen de las extensiones de la antigua jurisdicción y las demarcaciones de los límites del altepetl y de sus vecinos, por otro la comunidad confecciona su particular manera de entender el tlacauhtli. Ya Florescano (2002), Lockhart (1982), Gruzinski (1987) y Dehouve (1995) nos señalan que las fundaciones de los pueblos las antecedían ritos en los cuales participaban los miembros de la comunidad quienes cogían yerbas y las esparcían a los cuatro rumbos del cosmos o hacían algo similar con flechas, e iban recolectando piedras y maderas en el camino para la construcción del templo. En el caso del título de Ajusco, podemos observar el momento de fundación: 
Mi corazón está animado, recuerdo buscar establecer este pueblo, aquí, debajo de este montículo, Axochco Xalticpac, porque desde allá abajo, debajo- el lugar del pueblo Axoxhpaneca es grande. Esta tierra abajo ya es su patrimonio, [que] nuestros abuelos habían heredado a nosotros, aquellas de abajo ya eran su patrimonio exclusivo $[\ldots]^{14}$ (Megged 150)

Para, posteriormente, explicar "caminando" los lindes del pueblo:

De allí en adelante contesto ahora [que] reduzco nuestra tierra allí donde deseo que el empezará a establecer los límites hacia el oeste [donde] se pone el sol, llamándose Tzictecomatitlan se alcanzar. Corremos hasta el lugar llamado Tetzipictitlan serviremos de vuelta, crearemos el ponerse la preciosa luz del sol en el oeste, [al lugar] llamado Nopaltitlan, o caminamos hasta donde está llamando [fuente] de agua este Tlatiloyan. Llegamos al lugar llamado Cacalotl Ineman [el Cuervo Oriental], donde tomamos la vuelta, donde sale el sol, [allí] miraremos a la estrella arriba e iremos [hasta donde] se llama Tlatlatiloyan [Lugar donde se Guarda], vemos aquel que se llama Atla [Agua Salvaje], vemos aquel que se llama Tlecuilco [Lugar de Fogata], [que] estará pronunciada más allá de la estrella. Se aparecería hacia allá donde sale el sol, corremos al lugar llamado Tochtepec [Lugar del Conejo]. Vemos aquello que se llama Micca Oztoc [Cueva de los Muertos]. Vemos lo que es nombrado Itztal Tlali [Tierra Blanca]. Pues, en donde está con hielo, las mojoneras están cerradas, terminadas, al entrar [por la puerta] del cerro llamado Axochco Zacapan Xalan $[\ldots]^{15}$ (Megged 153)

14 Nehuatlninoyolchicahua niquilnamiqui nicmanaz inin altepetl nican itzintla ini tepetl Axochco Xalticpac ypampa ca ye tlatzintla mantoc inyeyan in axochpaneca ca ynin tlayi ye tlatzintla toaxca otechmocahuitehuaque toachcocolhuan ca inmaxcatzin ocatca zan ye tlatzintla).

15 Zan niman axcan nictequi $\mathrm{m}[\mathrm{n}$ ]icototzoa totlal Yez no tlanequili pehuaz to cuaxoch iquizanpa tonali pehuaz can in motocayotia Tzictecomatitlan, tianazqui ilhui yhualayan in cecuiztla tanique ca inin motoa Tetzipictitlan mo titlamacachozque titlachihuazque icalaquiampan in tonaltzintli, tanique ca inin mitoa Nopaltitlan, tihui ca inin motoa Atl inic tlatiloyan, tazique ca inon motoa cacalotl nicmian [Ineman] in titlamacachozqui icalaquiampa in tonali, titlachiazqui zitlali icuecpan ca, tiatihui ca inin motoa tlatlatiloyan tihui ca inin motoa tecuan Atla, tihiz ca inin motoa tlecuilco, inin nahuatizqui zitlali icuepanca, tlachitazque iquizayan pan in tonali' taniqui ca inin motoa Tochtepec, tihui ca inin motia Micca Oztoc, tihui ca inin motoa Iztlal tlali niman mi motzacuac in to cuaxochtzonquica, quiyahualoz in tepetl motocayotia Axochco que Uds. Me esuchen Zacapan Xalan. 
Fundar y marcar las fronteras del altepetl es, entonces, un ejercicio variado que involucra la historia del pueblo y, fundamentalmente, su relación con el tlacauhtli: con los rumbos del mundo y con su ordenamiento armonioso. Este, Oeste, Norte y Sur, los puntos cardinales del entorno, el tlacauhtli se relaciona con la historia y el tiempo, el cahuitl, conformando una relación difícil de separar. Es por esto que decimos que el título primordial no se formula como una representación del territorio, sino que es el territorio en cuanto a cómo lo vive la comunidad. En este espacio/tiempo se desarrolla la memoria de la comunidad, que no es más que la historia de la energías, de los tequitl de las generaciones pasadas y presente, confabulándose recíprocamente para originar al altepetl. 


\section{Bibliografía}

Anónimo. Título primordial de Santo Tomás de Ajusco. En Megged, Amos. "El "Relato de Memoria" de los Axoxpanecas (Postclásico Tardío a 1610 DC)": Relaciones. Estudios de historia y sociedad 31 (2010): 143-162.

Carrasco Pizana, Pedro and Johanna Broda. Economía política e edeología en el México Prehispánico. 1ra. ed. México: Editorial Nueva Imagen, Centro de Investigaciones Superiores, 1978.

Cook, Sherburne Friend, and Woodrow Wilson Borah. The indian population of Central Mexico, 1531-1610. Berkeley: University of California Press, 1960.

Dehouve, Danièle. Hacia una historia del espacio en la montaña de Guerrero. 1ra. ed. México, D.F.: Centro de Estudios Mexicanos y Centroamericanos, Centro de Investigaciones y Estudios Superiores en Antropología Social, 1995.

Florescano, Enrique. "El canon memorioso forjado por los títulos primordiales". Colonial Latin American Review 11.2 (2002): 183- 230.

Galarza, Joaquín, and Rubén Maldonado Rojas. Amatl, Amoxtli = El papel, el libro. Los códices mesoamericanos: guía para la introducción al estudio del material pictórico indígena. Colección Códices Mesoamericanas. 2da. ed. México: TAVA, 1990.

García Martínez, Bernardo. Los pueblos de la sierra: El poder y el espacio entre los indios del norte de Puebla hasta 1700. 1ra ed. México, D.F.: El Colegio de México, Centro de Estudios Históricos, 1987.

Gibson, Charles. The aztecs under spanish rule; a history of the indians of the valley of Mexico, 1519-1810. Stanford, California: Stanford University Press, 1964.

Good Eshelman, Catherine. "Ejes Conceptuales entre los Nahuas de Guerrero: Expresión de un Modelo Fenomenológico 
Mesoamericano". Estudios de Cultura Náhuatl 36 (2005): 87- 113.

Gruzinski, Serge. "Colonial Indian Maps in Sixteenth-Century Mexico." Res 13 (1987): 46- 61.

Jansen, Maarten E. R. G. N., et al. Códice Fejérváry-Mayer. Códices Mexicanos. 1ra. ed. Austria, México: Akademische Druck-und Verlagsanstalt; Fondo de Cultura Económica, 1994.

Jansen, Maarten E. R. G. N., Luis Reyes García, and Ferdinand Anders. Códice Borgia. Códices mexicanos. 1ra. ed. España, Austria, México: Sociedad Estatal Quinto Centenario; Akademische Druck- und Verlagsanstalt; Fondo de Cultura Económica, 1993.

Karttunen, Frances. An analytical dictionary of nahuatl. Austin: University of Texas Press, 1985.

León-Portilla, Miguel. Los antiguos mexicanos a través de sus crónicas y cantares. 1ra. ed. México: Fondo de Cultura Económica, 1961.

. Toltecáyotl: Aspectos de la cultura náhuatl. México, DF: Fondo de Cultura Económica, 2003.

López-Austin, Alfredo, Tamoanchan y Tlalocan. Sección de Obras de Antropología. 1ra. ed. México: Fondo de Cultura Económica, 1994.

Locke, John. The second treatise on civil government. Great Books in Philosophy Series. Buffalo, New York: Prometheus Books, 1986.

Lockhart, James. The nahuas after the conquest: A social and cultural history of the indians of Central Mexico, Sixteenth through Eighteenth Centuries. Stanford, California.: Stanford University Press, 1992.

Megged, Amos. "El "Relato de Memoria" de los Axoxpanecas (Postclásico Tardío a 1610 DC)". Relaciones. Estudios de historia y sociedad 31 (2010): 107- 162. 
Mignolo, Walter. "La Opción Descolonial." Letral 1 (2008).

Molina, Alonso de. Vocabulario en lengua castellana y mexicana y mexicana y castellana. México, D.F: Editorial Porrúa, 1970.

Sigal, Peter Herman. The flower and the scorpion: Sexuality and ritual in early Nahua Culture. Latin America Otherwise. Durham, NC: Duke University Press, 2011.

Soustelle, Jacques. El universo de los Aztecas. México, D.F.: Fondo de Cultura Económica, 1996.

Vitoria, Francisco de, Anthony Pagden, and Jeremy Lawrance. Political writings. Cambridge Texts in the History of Political Thought. Cambridge England; New York: Cambridge University Press, 1991. 